\title{
Impermissible Self-Rationalizing Pessimism: In Defence of a Pragmatic Ethics of Belief
}

\author{
Nikolaj Nottelmann ${ }^{1}$ B Boudewijn de Bruin²
}

Received: 10 January 2018 / Accepted: 8 January 2019 / Published online: 4 April 2019

(c) The Author(s) 2019

\begin{abstract}
We present an argument against a standard evidentialist position on the ethics of belief. We argue that sometimes a person merits criticism for holding a belief even when that belief is well supported by her evidence in any relevant sense. We show how our argument advances the case for anti-evidentialism (pragmatism) in the light of other arguments presented in the recent literature, and respond to a set of possible evidentialist rejoinders.
\end{abstract}

\section{Introduction}

Within the ethics of belief debate, a standard version of evidentialism characteristically claims that a believer believes as she ought to believe, if, and only if, her beliefs are adequately proportioned to her evidence. ${ }^{1}$ The stronger version of this thesis also claims that evidentialist norms reign supreme within the ethics of belief: that a believer believes as she should can be fully explained by her compliance with evidentialist norms (see, e.g., Adler 2002). The weaker form takes evidentialist norms to be derivative relative to deeper norms guiding belief. Evidentialism only holds because the class of beliefs satisfying those deeper doxastic norms is

\footnotetext{
${ }^{1}$ In taking this version of evidentialism as our starting point, we follow other recent treatments of the ethics of belief. E.g. Marušić (2011, pp. 33-34) has it that "according to evidentialism, one should believe something if and only if [one] has adequate evidence for what one believes". Obviously, some evidentialists have preferred alternative versions of evidentialism. Some of those shall play a significant part below.
}

Nikolaj Nottelmann nottelmann@sdu.dk

Boudewijn de Bruin

b.p.de.bruin@rug.nl

1 Department for the Study of Culture - Philosophy, University of Southern Denmark, Campusvej 55, 5230 Odense M, Denmark

2 Faculty of Philosophy, University of Groningen, Oude Boteringestraat 52, 9712 GL Groningen, The Netherlands 
contingently co-extensive with the class of beliefs satisfying evidentialist standards. An example of a purported deeper doxastic norm is a welfarist rule: Believe only in such a way that thereby you do not threaten general human well-being. On one reading, W.K. Clifford in his famous 1877 essay had it that a doxastic norm along those lines entails a standard version of evidentialism. ${ }^{2}$

This paper primarily aims to strengthen the case against standard evidentialism in the weaker as well as the stronger sense lined out above. So, we argue that the general (im)permissibility of beliefs cannot be fully accounted for by sole reference to the standard evidentialist norm, and also that there are circumstances under which plausibly an agent does not believe as she ought to, even if she has adequate evidence for her belief. ${ }^{3}$ Ours is a 'strong' pragmatism since it contradicts the stronger as well as the weaker version of standard evidentialism. ${ }^{4}$

Clearly, the standard version of evidentialism presented above has not been accepted by all evidentialists. In fact, even within the ethics of belief debate, evidentialism has come in so many exotic flavours that we cannot hope to cover them all (see here, not least, Chignell 2017, Sect. 4). However, we aim to show below that our argument also creates problems for other influential, albeit more complex, versions of evidentialism concerning the ethics of belief. E.g. Andrew Chignell in his recent comprehensive overview assumes the most standard version of evidentialism to involve a basing requirement: "The central principle [of evidentialism]....is that one ought only to base one's beliefs on relevant evidence...that is in one's possession" $(2017,23)$. Due to the many controversies over the notion of basing (see e.g. Sylvan 2016), this is a more difficult and complex version of evidentialism to work with. Nevertheless, we hope to argue (see Sect. 5.5) that no standard account of the basing relations offers evidentialists a safe retreat to this alternative position once our argument against the simpler standard version of evidentialism has been accepted. Also, we shall consider and reveal as problematic any retreat to a position requiring for permissible belief anterior doxastic justification construed along evidentialist lines (see Sect. 5.1).

While this article is certainly not the first to defend strong pragmatism (see Sect. 4), arguably it has virtues not found in combination elsewhere. Importantly, our defence does not involve believers believing 'against their evidence'. 5 Moreover, our argument does not require the rejection of any non-deontic evidentialist theory

\footnotetext{
${ }^{2}$ Clifford's evidentialism is famously unrelenting and universal: 'it is wrong always, everywhere, and for any one, to believe anything upon insufficient evidence' (Clifford 1999, p. 77). But it seems weak in the sense presently adopted, as he invariantly defends it by reference to welfarist considerations such as avoiding that society 'sinks back into savagery' (Clifford 1999, p. 76) or 'is rendered in pieces' (Clifford 1999 , p. 75). The exact link between his welfarist and evidential considerations is a matter of considerable controversy, however. See e.g. Haack (1997) and Madigan (2009) for discussion.

3 We assume here that an unqualified doxastic prescription such as 'Marc ought to believe that P' is an ethical prescription. We believe this assumption to be consistent with general practice in the relevant debates, as the ethics of belief is fundamentally concerned with what subjects ought (not) believe.

4 We follow the well-established use of 'pragmatism' as shorthand for anti-evidentialism (see, e.g., McCormick 2015; Reisner forthcoming). This does not, of course, entail a commitment to the views of truth or meaning associated with such philosophers as C.S. Peirce, William James, and John Dewey.

5 The title of McCormick's (2015) book indicates that this requirement features prominently in her defence of pragmatism (McCormick 2015).
} 
of epistemic justification. ${ }^{6}$ Finally, avoiding exotic thought experiments, we appeal to fairly mundane psychological mechanisms supported by ample empirical evidence. Thus, unlike key pragmatic arguments in the recent literature, our argument cannot be rejected due to scepticism regarding the validity of thought experiments involving unrealistic scenarios, and hence should appeal to a broader audience. ${ }^{7}$ As a bonus, our argument brings outs the actual practical significance of endorsing pragmatism rather than standard evidentialism.

The crucial component in our argument is the phenomenon of 'self-rationalizing' belief. Roughly, a belief self-rationalizes whenever someone's holding it offers her sufficient evidence for its content's being true. Our primary aim is to show that certain self-rationalizing beliefs are impeccable from a standard evidentialist point of view, but should be condemned by general belief-guiding norms. We are fully aware that some evidentialists will most likely consider our argument inconclusive. Very few, if any, counter-examples in the philosophical literature have appealed to everyone. To this audience, at least we hope to have made further explicit the strength of the case against standard evidentialism.

The structure of the paper is as follows: Sect. 2 explains the concept of selfrationalizing belief. Section 3 presents and discusses our case of illegitimate selfrationalizing belief. Section 4 contrasts our argument with relevantly similar recent arguments offered in support of pragmatism. Section 5 considers and refutes several potential evidentialist rejoinders. Section 6 concludes.

\section{Self-Rationalizing Belief}

A belief is self-rationalizing, whenever someone's holding it offers her evidence, which, at least pro tanto, constitutes sufficient reason for believing its content. This concept should be distinguished from beliefs with self-evident (or truistic) content. The sense in which the positive evidential status of such a belief is guaranteed is not the relevant one, because its content is supported by our evidence no matter whether we hold the belief or not. In other words, our believing such propositions provides no further evidential support for them. We may note in passing that this is the case irrespective of the modal status of their contents. Arguably there are metaphysically necessary truisms like 'All beliefs are beliefs' and contingent truisms like 'I am thinking now' or 'I am here now'. Beliefs with such contents are

\footnotetext{
${ }^{6}$ E.g. we have no quarrel with Vahid's evidentialist statement that 'although pragmatic considerations can be epistemically relevant, they still fail to rationalize belief in the truth-conducive sense of the word' (Vahid 2010, p. 461). Still, of course we are committed to deny the conjunction of the deontic theory that epistemically justified belief equals ethically permissible belief with any standard evidentialist theory of epistemic justification. If we were forced to accept the latter conjunct here, we would have to deny the former.

7 See e.g. Young (2013) and Machery (2017). Such skepticism has become increasingly widespread in the metaphilosophical literature, not least following reviews of studies conducted by experimental philosophers and cognitive psychologists. We should stress that we do not here commit to this type of skepticism ourselves. Only we hope to make pragmatism more appealing to readers of this persuasion. We thank an anonymous referee for this journal for pressing us on this issue.
} 
not self-rationalizing, though, even if it seems (almost) impossible to believe them irrationally.

The matter is somewhat subtle, since some self-rationalizing beliefs have contents, which are close to truistic. We are thinking here of beliefs with contents such as 'I have at least one belief' or 'I have at least one self-referential (de se) belief'. Since typical believers will have ample evidence for the truth of such propositions, we can normally ignore the difference between the epistemic status of such a content considered as a standing belief (ex post) in opposition to its being considered as a mere candidate for belief (ex ante). So evidentially it typically matters little whether such a content is believed or not. However, at least hypothetically there could be cases where a believer's holding the beliefs in question would constitute a significant evidential difference for her; for instance, when a subject's belief that she has at least one self-referential belief is in fact her only de se belief.

Andrew Reisner has coined the term 'auto-alethic belief' for any belief such that 'your believing it will secure the belief's truth' (Reisner forthcoming, p. 17). This notion plays a key role in his arguments for pragmatism (see Sect. 4). However, even if Reisner's notion of auto-alethicism has partly inspired our notion of self-rationalization, the concepts are importantly different: Auto-alethicism is neither necessary nor sufficient for self-rationalization in the present sense. ${ }^{8}$

Non-sufficiency first. Imagine that there is a brain state $X$ such that my belief ' $I$ am in brain state $X^{\prime}$ suffices to bring me into brain state $X .{ }^{9}$ Even if my belief that I am in brain state $\mathrm{X}$ is auto-alethic, it is not for that reason self-rationalizing. Even if I happen to be in brain state $X$ in virtue of believing that I am in brain state $X$, from an epistemic perspective my belief to be in brain state $X$ may be entirely unsupported, as nothing guarantees that I possess adequate evidence that $\mathrm{I}$ am in brain state $X$, or for that matter, that I possess adequate evidence to the effect that my believing to be in brain state $X$ causes me to be in brain state X. My belief that I am in brain state $\mathrm{X}$ is auto-alethic, but not self-rationalizing.

Nor is auto-alethicism necessary for self-rationalization. This is because a belief can self-rationalize even if it is false. A self-rationalizing belief can even be selffalsifying. A subject's brain may, for instance, be so wired that her belief 'I will be happy in two minutes' not only triggers intense and seemingly very robust feelings of happiness, but also her sudden physical death within a minute. Auto-alethic and self-rationalizing beliefs, then, are not the same. ${ }^{10}$ This will be of importance to our argument below.

\footnotetext{
8 Anticipating a more detailed discussion in Sect. 4, Reisner's key arguments for pragmatism do not rest on auto-alethicism as proclaimed, but rather on known auto-alethicism (auto-alethicism the agent is aware of), which is a special case of self-rationalization.

9 How this story could go obviously depends on one's preferred metaphysics, but this is unimportant here.

${ }^{10}$ Of course, some auto-alethic beliefs also self-rationalize. If you are a neuroscientist knowing that a guaranteed way to enter brain state $\mathrm{X}$ is simply adopting the belief ' $\mathrm{I}$ am in brain state $\mathrm{X}$ ', that is an autoalethic belief that will also self-rationalize, because you will then have evidence that you are in brain state X.
} 
A final caveat is in order before proceeding. We should be careful to distinguish self-rationalizing beliefs from beliefs that are only apparently self-rationalizing. A belief only apparently self-rationalizes when, for instance, the belief and the production of evidence for it are independent effects of a common cause. Suppose I promise a friend to meet her in Venice a week from now. Since I am the kind of person who sticks to such promises, making that commitment induces me to believe that I will soon be in Venice. Also, arguably, my firm memory of making the promise provides sufficient evidence to support my belief, at least pro tanto. But my belief is not for that reason self-rationalizing in our sense of the word.

With these introductory clarifications in place, we propose the following basic taxonomy of types of self-rationalizing beliefs:

Constitutive or direct self-rationalization.

(1a) Atomistic The fact that she holds the belief in itself constitutes evidence for the believer, which gives her sufficient reason for holding it, at least pro tanto

(1b) Holistic The fact that the belief is held constitutes sufficient evidence ${ }^{11}$ for it on the background of the believer's total evidence.

\section{Causal or indirect self-rationalization.}

(2a) Atomistic The fact that the belief is held in itself suffices causally to produce sufficient evidence for it.

(2b) Holistic The fact that the belief is held, non-redundantly and together with other obtaining facts, causally suffices to produce sufficient evidence for it.

We do not have anything significant riding on (1a) and (2a) having realistic instances; these types are included for the sake of completeness. Types (1b) and (2b), however, are centrally relevant here. Arguably, the latter type often works by a mechanism of the following general kind:

(A) Believer $\mathrm{S}$ adopts and subsequently sustains a belief that $\mathrm{P}$

(B) Given her other mental states, S's believing that $\mathrm{P}$ affects her behaviour in a characteristic manner $\mathrm{M}$

(C) In virtue of $\mathrm{M}$, S's environment displays a characteristic response $\mathrm{R}$ to $\mathrm{M}$

(D) In virtue of R, S's evidence for $\mathrm{P}$ is further bolstered

We will see below that some cases of self- rationalizing pessimism ${ }^{12}$ fit this schema particularly well.

\footnotetext{
11 For ease of presentation, here and below we shall use "sufficient evidence for belief p" as short for "evidence constituting, for the relevant believer, pro tanto sufficient reason for belief p".

12 The term 'pessimism' could denote several different phenomena. Here we shall speak primarily of 'pessimistic belief' being belief in the high likelihood of undesirable outcomes. We thank an anonymous referee for calling attention to the need for this clarification.
} 


\section{A Case of Self-Rationalizing Pessimism}

With the concept of self-rationalizing belief in place, we now present our central case. It is built on well-established empirical work in the psychology of belief formation. ${ }^{13}$ It is important to note that cases relevantly like this case are entirely realistic, even common. Also, we do not mean to argue from any armchair empirical claims about how subjects would respond to the below "vignette" considered in isolation. Rather, our presentation of the case and our subsequent discussion is meant to trigger the reader's understanding of - and sense of familiarity with — the relevant type of case and its typical normative status.

(Marc) Marc is a healthy and normally gifted adult psychology student about to enter a mandatory statistics course. He has ample evidence to suggest that pessimists about their success in that course tend to do badly at statistics. Rather spuriously, Marc himself becomes a pessimist by forming the belief that he will never do well at statistics. Influenced by that belief, every time he is assigned a problem that requires more than very modest efforts, Marc takes his failure effortlessly to solve it as a sign that statistics is beyond his ken. Thus, he hands in most of the homework assignments largely blank. Consequently, he learns very little and receives very poor grades. So, over time Marc acquires exceedingly strong evidence that he will never do well at statistics.

The above example exhibits direct, holistic (1b) self-rationalization followed by indirect, holistic ( $2 b$ ) self-rationalization, exhibiting the feedback pattern mentioned above. Marc's pessimistic belief leads him to invest little by way of studying statistics; the environmental response is Marc's receiving bad grades (plus his observing that as the course progresses he turns out to find the problems increasingly difficult to solve). The environmental response in turn evidentially bolsters Marc's pessimistic belief, eventually going through a vicious feedback cycle. In contrast, Reisnerstyle auto-alethicism hardly occurs. Even when Marc's belief that he shall never do well in statistics becomes highly well-proportioned to his evidence, this does not rule out that sometime, somehow, he becomes an excellent statistician. In principle, Marc's evidence in favour of pessimism is even compatible with his being already

\footnotetext{
13 The literature is large. See, e.g., Carver and Scheier (2014) (general review of psychology literature), Klassen (2004) (cross-cultural variation) and Bénabou and Tirole (2016) (recent work in economics). A philosophically informed review is due to Bortolotti and Antrobus (2015). Our case below is an instance of a more general phenomenon. In the economic realm, self-rationalizing pessimism explains, for instance, the relative differences in job market qualifications between various social groups in the US as well as differences in household finances, and is a crucial factor explaining discrimination in the house market [see, e.g., Swire (1995) and Arrow (1998)]. This phenomenon must not be confused with the negative effects of stereotype threats, where someone's becoming aware of a negative stereotype concerning the group they belong to takes up a considerable amount of 'mental capacity' (Steele 2010, p. 121) with the result that they perform worse than they could have on quantitative, athletic, and a host of other tasks. One might wonder whether the recent crisis of replication affects these findings. To lower the likelihood that it does, we here refer to results from various disciplines (psychology, economics), using various methods (lab experiments, natural experiments, econometric work on secondary data collected by national statistical bureaus, more theoretic work in microeconomics).
} 
excellent at statistics, yet having not manifested this ability due to incredibly bad luck. If we are right that cases like Marc's are common, this goes to show that selfrationalizing belief is a widespread phenomenon, which an ethics of belief can only ignore at the peril of gross inadequacy in the actual world. In contrast, even if we have not shown that auto-alethic beliefs do not occur, we have at least made plausible that they are exotic phenomena as compared to their self-rationalizing cousins. Our below reflections on Reisner's appeals to auto-alethic belief in defence of pragmatism (see Sect. 4) shall serve further to bolster this claim.

Back to the case. Observe that even though Marc might have done very much better given a less pessimistic initial attitude, there is nothing clearly wrong about his doxastic history as seen through a standard evidentialist lens. Once formed, his pessimistic belief is entirely rational, evidentially speaking, owing to its self-rationalization. At the same time, though, Marc has strong pragmatic reasons not to be so pessimistic. It is highly likely that Marc's self-rationalizing pessimism hurts his own career prospects and his self-esteem. To the extent that he actively spreads his pessimistic attitude, he may even harm his co-students through contagion. Some of this likely harm is epistemic in a consequentialist sense. Marc's pessimism frustrates the goals of gaining truth and avoiding error (no matter how these goals are defined more precisely): He fails to gain many of the true beliefs about statistics he could have gained, and fails to realize many true beliefs in domains whose proper understanding requires a certain amount of statistical knowledge. This affects Marc just as it affects epistemic agents that might trust him as a source of information on such topics, as they would run a higher risk of error and lose out on forming true beliefs. Yet the relevant harms are hardly confined to the merely epistemic. Suppose, for instance, that Marc becomes a clinical psychologist. Then his lack of statistical knowledge may severely limit his diagnostic and therapeutic success, or even lead to plain therapeutic errors. Marc is, for instance, unlikely to possess the critical reasoning skills necessary for the sophisticated implementation of evidence-based treatments.

Exactly how, in general, evidential reasons for belief should be weighed against pragmatic reasons remains a contentious issue (see, however, Reisner 2008). Nevertheless, it seems plausible that in cases like Marc's, pragmatic reasons have the upper hand: Remember that Marc's evidential reasons are created, so to say, through self-rationalizing. His harmful pessimism is not a matter of properly adjusting his attitudes to the prior state of the world. If this is right, Marc and similar self-rationalizing pessimists have an all-things-considered reason not to hold their pessimistic beliefs. At least in one sense, then, they ought not be pessimists, despite their pro tanto sufficient evidential reasons for pessimism. This refutes the right-to-left implication of standard evidentialism: That a subject's beliefs are adequately proportioned to her evidence does not entail that she believes as she ought to.

Whether agents like Marc deserve any degree of blame or reproach for their harmful pessimism is a more controversial issue. Still, we shall argue that plausibly they sometimes do. For the present purposes we shall endorse the following weak Control Principle: 
CP-Weak: If, by way of her current state, (1) an agent is at significant risk of causing significant harm and (2) it is within her power to cause herself to change, such as no longer to be at significant risk of causing significant harm, and (3) she is aware of the potentially harmful nature of her current state and also aware of the fact that she could change herself such as not to be at significant risk of causing significant harm, and (4) nevertheless, she makes no effort to change herself such as not to be at significant risk of causing significant harm, then she is blameworthy for remaining in her current state.

Given CP-weak, we submit that it would not be unjust or insensitive to reproach at least some agents in Marc's position for sustaining their pessimistic belief (at least in the early stages of their pessimism). We are not here suggesting that any agent is in any way obliged to achieve the impossible task of believing against overwhelming contrary evidence, as most likely obtains in Marc's case after some time. Nor do we want to claim that agents like Marc are necessarily the only ones to blame for their pessimism. Blaming some of them is fully consistent with the view that the misadventures of many normally gifted students may partly be caused by systemic failures in our educational systems. Finally, CP-weak of course does not entail that agents should ever be blamed, if their pessimistic beliefs about educational success are part of an inert and more generally grounded pessimistic attitude, such as would arise from a severe clinical depression.

One important objection, however, stands in the way of blaming Marc in the first place: Since Marc's pessimistic belief is evidentially rational as soon as he has formed it, evidentialists may argue that it is always 'at the mercy of [Marc's] evidence', and is therefore always out of his direct control. ${ }^{14}$ Thus, it is psychologically impossible for agents in Marc's situation to satisfy condition (2) of CP-weak.

We submit that this challenge can be met. Marc's early pessimism was not based on personal bad experiences with statistics. Therefore, he had a vivid psychological opportunity to suspend judgement concerning future success in statistics courses. Even though full-blooded optimism may have been out of reach for him even then, he was not forced to sustain his pessimism. Also, he may well have been in a position to know how he could escape it.

Let us say a little bit more about the psychological reality of those claims. Neuroscience research on 'voluntary forgetting' suggests that people can voluntarily extinguish certain bits of evidence from memory through blocking it once it becomes activated, or by actively replacing it by other facts. Concretely, the strategy neuroscience might recommend to Marc is that as soon as he becomes aware of his pessimistic thoughts about statistics, he actively focuses on a difficulty that he successfully coped with, thereby replacing the pessimistic thought with an optimistic one. ${ }^{15}$

\footnotetext{
14 Feldman, e.g., contests that we may at best control our beliefs indirectly by virtue of controlling our evidence, even if still we believe 'at the mercy of our evidence' (Feldman 2001, p. 83).

15 See, e.g., Benoit and Anderson (2012). They also show that another strategy is not to replace; but to suppress, the negative thoughts. They use fMRI to demonstrate that the two strategies (replacement or suppression) harness different parts of the brain.
} 
Secondly, there is evidence showing that people can actively control their beliefs through the conscious selection of two different belief formation principles. Faced with a body of evidence $\mathrm{E}$ in favour of some proposition $\mathrm{P}$, you can ask whether on the basis of E you can believe that P; or you can ask whether you must believe that P. Surely, since the latter principle leaves more room for doubt and scepticism, it is more likely than the former to lead to suspension of belief. ${ }^{16}$ Apart from the strategy of voluntary forgetting, Marc could at some stage, then, have applied the 'must I believe that' principle to his pessimism about statistics.

Nor is this all. Marc may well be assumed to know (for instance, from an earlier course in psychology) that having pessimistic beliefs about a particular task may raise the likelihood of failing that task; pessimism may reinforce itself. He may counter his pessimism about statistics with a very concrete bit of evidence to the effect that should he fail, very likely this would be because of his pessimistic condition rather than because of the skills he brought to the statistics course.

Unsurprisingly, the powers of positive thinking have not gone unnoticed in the evidentialist tradition. Clifford opens his 1877 article with a story about a scheming ship-owner, who- through self-suggestion and successful efforts towards forgetting contrary evidence-manages to convince himself that his ship is seaworthy, when in fact it is badly in need of repair. Thus, he sends his trustful passengers to a wet grave. Clifford relentlessly condemns the ship-owner's opportunistic strategy: 'he was verily guilty of the death of [the passengers]' (Clifford 1999, p. 70), since 'he had knowingly and willingly worked himself into that [optimistic] frame of mind' (Clifford 1999, p. 71). As should already be clear, we deem Clifford too hasty in drawing a general evidentialist conclusion from an observation concerning the perversity of cynically exploiting positive thinking for personal gain. Like Miriam Schleifer McCormick, we concede to Clifford that 'believing against the evidence tends to be harmful, both to the individuals and to the collective' (McCormick 2015 , p. 53). Still, when a generally harmful self-rationalizing belief is involved, as in Marc's case, arguably evidentialism yields the wrong ethical verdict. Here the harnessing of positive thinking for belief revision not only is ethically permissible, it may even be ethically required. ${ }^{17}$ From a standard evidentialist perspective, obviously, it would be madness for Marc to work towards abandoning a rational belief with any chance of acquiring ever firmer evidential grounds. But so much the worse for standard evidentialism.

\footnotetext{
${ }^{16}$ Numerous studies attest this phenomenon, e.g. in a health care context (Oster et al. 2013). A highly readable (though slightly outdated) introduction is Gilovich (1991).

${ }^{17}$ We are not committed to recommending positive thinking in cases structurally dissimilar from the Marc case. Even if nothing hinges on this in the present context, we find positive thinking highly problematic when it serves to disguise or perpetrate social injustice, or when it leads to postponing the alleviation and remediation of suffering. And of course, where positive thinking fails to work (as in treatments of many somatic diseases), it should not be recommended.
} 


\section{Alternative Recent Arguments for Pragmatism}

The Marc case aims to build an argument for strong pragmatism. For the purpose of underscoring the novelty and relevance of our argument, we now briefly discuss some recent alternative pragmatist arguments to the conclusion that evidential reasons alone cannot ensure that one believes as one ought to.

We shall give special attention to Reisner's appeals to auto-alethic belief, which have in great part inspired the current paper. Above we have already noted that selfrationalizing is a different phenomenon from auto-alethicism, and of wider ethical significance, at least in the sense that it is likely to occur under more mundane circumstances. Still Reisner's ingenious examples demand careful attention.

One of his cases involves a seriously ill patient knowing that a lack of optimism about recovery from his type of illness ensures the terminality of that illness (Reisner 2013, pp. 179, 180). This knowledge induces in the patient a pessimism that dooms him. ${ }^{18}$ First, however, this case is less straightforward than ours, since the pessimistic belief is only auto-alethic (and self-rationalizing) due to its exclusion of a relevant optimism, which would have saved the patient. Secondly, any normative verdict here is complicated by the fact that the patient is terminally ill, and knows this. Compared to our case, we find it much harder to say what such an afflicted agent ought (not) believe. There is (fortunately, we believe) no established practice for criticizing the doxastic behaviour of terminally ill agents rather than pitying them.

Another of Reisner's examples involves a neurotic basketball player Smith, plagued by an unfortunate mechanism linking his beliefs about his chances of freethrow success to his objective chances thereof: If Smith believes his chance of sinking his next free-throw is $\mathrm{x} \%$, his actual chance of sinking it instantly becomes $x-5 \%$, if $x>5$, or $0 \%$, if $x \leq 5$ (Reisner 2008, p. 22). Smith is fully aware of this. Thus, the only stable evidentially well-grounded belief he could have about his chances of sinking his next free-throw is an auto-alethic belief in certain failure! Nevertheless, if Smith stands to win a huge donation to a deserving charity by sinking his next free-throw, he would seem to have overriding (or, in Reisner's terms, "silencing") pragmatic reasons for believing in a positive chance of sinking the shot (ibid.).

Clearly, the supposition of a strange mechanism linking objective success rates in basketball to an agent's belief contents in such a rigorous manner radically defies our common knowledge of how the world works. Not least since it is very hard how to see how Smith's objective chances of success could possibly depend only on his mental state in such a fine-tuned manner, and how it could ever be reduced to exactly $0 \%$. How could the condition of the ball, the condition of the hoop, or Smith's current physiological state fail to be of any relevance? And given that he even cares to let go of the ball, could not it always end up in the basket due to a fortunate gust of wind? It may be argued that Reisner could have relied on much less

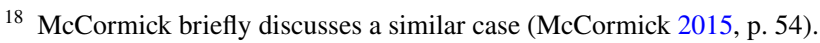


fantastic assumptions. E.g. that all he needs is that Smith is made nervous by knowing his chances and knowingly does worse because of that. Without a rigorous feedback mechanism however, the example will not give Reisner the result he needs: that Smith's knows his only stable, evidentially permitted belief, to be the belief that he shall necessarily fail. ${ }^{19}$ We shall not go so far as to rule out the value of Reisner's case for supporting pragmatism. But certainly, it will hardly sway readers skeptical of verdicts passed on very weird counter-factual scenarios. ${ }^{20}$

The same could be said about Reisner's more recently preferred example of autoalethic belief. Here a subject $S$ is attached to a mind-reading apparatus with the following properties: If $\mathrm{S}$ forms the belief that the number $\mathrm{n}$ will appear on a monitor, $1 / 2 n+1$ will show on that monitor a minute later for $n>0$, and $1 / 2 n-1$ for $n \leq 0$; if $S$ doesn't form a belief about some number's appearing on the monitor, the number 16 will show; and if $\mathrm{S}$ revises her beliefs before the monitor has shown a number, the process will start over again. $\mathrm{S}$ knows all of this. Therefore, only two options are psychologically viable to her: to believe that -2 - or to believe that 2 will display. (S knows that all other beliefs are self-falsifying.) As it stands, both beliefs are equally permissible from a standard evidentialist perspective. To yield a positive case for pragmatism, Reisner need only add one further ingredient in the form of a non-evidentialist reason in favour of, say, believing that 2 rather than -2 appears. $S$ may supposedly be awarded a valuable prize for adopting the former belief. In that case, Reisner concludes that at least now the onus of proof is upon evidentialists to explain why it is not the case that the subject ought to believe that 2 will appear, whereas her believing that -2 will appear would merit criticism (Reisner forthcoming, pp. 24, 25).

Here are the main problems with this example, as we see them: First, Reisner's explanation why the 2-belief and the -2-belief are equally evidentially permissible rests on his claim that 'it is always epistemically permissible to believe, and to come to believe, an auto-alethic belief' (Reisner forthcoming, p. 17). This claim is dubious, though, because beliefs may be auto-alethic only because they self-verify in entirely evidence-transcendent ways (see, for instance, the case with the non-detectable brain-state in Sect. 2).

Second, Reisner's argument is dependent on S's possessing knowledge about the relevant beliefs' self-verification. It is, however, unclear what body of evidence evidentialists should accept as warranting ascribing such knowledge to S. Reisner submits that S knows, since she "understands the operations of the apparatus perfectly" (forthcoming, p. 16). But from this it hardly follows that she also knows the machine to work as intended on every occasion. For her to test, for instance, whether her believing that 2 will appear on the monitor in fact causes the monitor to display 2 would naturally involve her trying out whether a 2-belief leads to an appearance of 2 on the screen. But it is hard to make sense of such a test. If, at the initial stages of her testing the reliability of the machine she has no conclusive evidence about its well-functioning (even if she understands its operations), she can hardly make

\footnotetext{
19 We thank an anonymous referee for pressing us on this point.

20 See e.g. the references mentioned in note 7.
} 
herself believe that 2 appears on the screen just to check whether 2 will appear. Thus, it is hard to tell why she trusts the machine so deeply, since she will not be able to get inductive evidence of well-functioning from the machine's responses. Reisner's stipulation that $\mathrm{S}$ simply trusts the machine seems rather gratuitous.

Finally, even if S knows that 2 will appear when she believes it, the setup is such that she also knows that, should she abandon her 2-belief (as she very easily could, since her choice of this belief over a -2-belief is entirely capricious), the monitor will not show 2 . Her present belief that 2 will appear is therefore insufficient autoalethically to ensure 2's appearance; it has to be accompanied by the belief that $\mathrm{S}$ will not change her belief during the next $60 \mathrm{~s}$. Now, surely, given that she knows the entire experimental set-up (and knows she won't forget it $60 \mathrm{~s}$ hence), she knows she will not believe in any number except 2 or -2 . But since at any time she can switch to -2 at no evidentialist costs, seemingly she has no reason to be sure that she will not change to -2 . And if she allows for the possibility that she changes within a minute, she may not even succeed in adopting a sufficiently firm attitude towards 2 in the first place. Notice that this verdict does not rest on any degree of general scepticism about future contingents. It is perfectly consistent with ascribing to $\mathrm{S}$ a great deal of knowledge about the machine's contingent future behaviour. E.g., most likely she knows that soon it will show some number on its monitor instead of breaking down. Even if this proposition is also a future contingent, unlike the proposition that the number 2 will appear, it is not contingent upon her rationally underdetermined whims. $^{21}$

Reisner's most recent example then seems to build on several quite fantastic suppositions, at least some of which are difficult to grasp. In conclusion to this section, we maintain that our case of self-rationalizing, yet impermissible, pessimism constitutes a non-redundant contribution to the case for pragmatism. We now turn to addressing possible evidentialist lines of reply to our argument.

\section{Six Evidentialist Lines of Response Considered}

We consider six evidentialist objections that may be marshalled against our proposal that Marc does not believe as he ought to, since he believes contrary to his strong pragmatic reasons, even if he has pro tanto sufficient evidential reasons for his belief: (1) Marc has responded inadequately to evidence; (2) what he has is not evidence; (3) the strength of his evidence is insufficient for general reasons; (4) the strength of his evidence is insufficient for pragmatic reasons; (5) His pessimist belief is impermissible, since it is not based on his evidence; (6) He does not behave as he ought to, but not because there is anything wrong with his pessimistic belief.

${ }^{21}$ We thank an anonymous referee for pressing us on this point. 


\subsection{An Inadequate Response to Evidence? The Case for Anterior Doxastic Justification}

To begin with, you might say that Marc does not believe as he ought to, only because his pessimistic belief was not formed as an appropriate response to his anterior evidence (even though, once formed, his belief was indeed adequately proportioned to his evidence). As an objection to our primary claim, however, this response fails to be effective for at least two reasons. The first is that standard evidentialism was construed as a thesis about the normative status of beliefs, not 'belief formations.' As an ethics of belief, standard evidentialism cannot directly prescribe against adopting particular beliefs; it can only prescribe against possessing particular beliefs, namely those that are insufficiently backed by evidence. Indirectly, then, it can also prescribe against beliefs, which would be thus ungrounded, once possessed. But since the pessimistic belief Marc possesses is never ungrounded, standard evidentialism cannot find fault with it.

You might suggest an easy fix by adding to standard evidentialism a clause entailing a proscription against beliefs owing their positive evidential status to self-rationalization only. The most obvious idea here would be to disallow beliefs, whose propositional contents were not adequately supported by the believer's evidence prior to belief-formation. In other words: To require for permissible belief not only propositional-but also doxastic - justification evidentially construed.

We acknowledge that this move is open to evidentialists, and also that it will effectively block our argument. And it is not ad hoc. Indeed, at least in many cases forming a belief without doxastic justification seems in some sense "reckless".

Still, we deem this counter-move problematic in the present context. On pains of consistency the resulting version of evidentialism would also have to rule against highly beneficiary specimens of self-rationalization. E.g. it would have to deny the concert pianist her right to her well-grounded belief that she can successfully play Beethoven's monstrous Hammerklavier sonata in a case where her having formed that belief is a crucial part of her evidence that she can in fact accomplish this demanding feat. Surely this is an unwelcome consequence. Arguably, living a successful human life often does require building up a certain level of self-confidence, which would not be sufficiently evidentially supported without it.

\subsection{Restricting What Counts as Evidence}

This idea is to impose restrictions on what counts in any way as evidence such as to make sure that Marc's pessimistic belief is not evidentially permissible. (This line of reply should not be confused with the response considered right below: Restricting what counts as sufficient evidence.) In the literature, there is significant disagreement on what counts as an epistemic agent's evidence. Famously Timothy Williamson has insisted that only known propositions count as evidence, whereas others have attacked that thesis (see, e.g., Brueckner 2009; Williamson 2000, Chapt. 9). Still, surely it would be ad hoc for evidentialists to tailor their notion of evidence, such that perfectly mundane candidates for being evidentially well-supported, yet 
impermissible, beliefs, come out as not backed by sufficient evidence after all. We submit that Marc's is such a case.

\subsection{Scepticism}

A third evidentialist option would be to raise the evidential standards, such as to escape the concession that Marc has sufficient evidence for his belief. But imposing such demanding requirements for evidential permissibility is a strategy that quickly backfires. If Marc does not have sufficient evidence here, many other seemingly permitted beliefs will no longer be acceptable to evidentialists either. This is because Marc's pessimistic belief may well be grounded by a mundane type of inference we should not want to abandon. It has the following form: Marc believes he is an A (a pessimist); he believes that As tend to be Bs (pessimists tend to be persistent failures at statistics); and so he believes he is a B (a persistent failure at statistics). Further, his pessimistic belief will soon be backed also by the following line of equally unproblematic reasoning: Everything of relevance to his being a failure at statistics that Marc will have observed will in fact indicate that he is; it seems highly unlikely that he will later observe anything indicating that he is not a failure at statistics; so he concludes that he will always be a failure at statistics.

To escape the conclusion that Marc has sufficient evidence for pessimism, evidentialists would have to disallow all beliefs grounded in structurally similar ways. This rules out so many of our everyday beliefs that it would ultimately amount to proposing a sceptical position that, while coherent, is also highly unattractive. ${ }^{22}$

\subsection{Pragmatic Encroachment}

Another argument questioning the sufficiency of Marc's evidence for pessimism appeals to the stakes involved in his case. Since the stakes are high, so this story would go, the evidence Marc needs in order permissibly to believe that he will fail the statistics course should meet higher standards. Any appearance that Marc's pessimism is sufficiently evidentially substantiated must be grounded in one's failure to notice that the relevant evidential standards have been pragmatically encroached upon: the pragmatic significance of his pessimism makes it the case that any applicable evidentialist standards are extra demanding.

Such a strategy may escape the dialectical problems marring the sceptical response considered above. It defeats our analysis of the Marc case without implying a wholesale condemnation of important parts of human doxastic life. But in return, the response forces evidentialism to concede a lot to pragmatism; for even if the

\footnotetext{
22 You wouldn't, for instance, be permitted to believe that you'll safely cross the road on the basis of ample evidence of safe crossings by similar pedestrians under similar conditions. Clearly abiding by such rules would be crippling to our lives without the promise of benefits. The famed ataraxia associated with Pyrrhonic scepticism is elusive when the proposition is of practical importance: there is little peace of mind gained from not believing you can safely cross a road when you badly need to cross it to rescue a distressed toddler. See, e.g., Bett (2014).
} 
resulting kind of evidentialism still respects Clifford's view on the impermissibility of believing on insufficient evidence, what counts as sufficient evidence would now be at the mercy of pragmatic considerations.

Nor is it so clear that this concession to pragmatism is helpful here. In stock cases of pragmatic encroachment, the evidential threshold for belief rises as the practical costs of being mistaken increase. The classical case being Keith DeRose's bank customer, whose evidence may well permit her to believe that the bank is open when nothing much depends on her being right, but does not permit that same belief when her financial well-being crucially rests on its truth (DeRose 2009, pp. 1, 2). However, the case of Marc is very different. In a typical case of pragmatic encroachment, an agent is confronted with several actions the potential consequences of which the agent evaluates very differently (that is, they differ a lot in their utility): the stakes are high. This means that before choosing a course of action, the agent wants to be very sure about the consequences of these actions. So, since a lot depends on it, it may take more for the agent to possess knowledge of these consequences. That higher evidential standards may be required for pragmatic reasons, then, is to say that higher evidential standards are necessary for an agent to select the optimal action in a high-stake case.

In Marc's case, however, higher evidential standards are of no avail. Unlike DeRose's bank customer, Marc is not well served by highly warranted beliefs about the consequences of the actions he can select. Rather he would benefit from suspending judgment on one particular proposition: that he will fail at statistics. While DeRose's customer has pragmatic reasons to be as certain as possible about the truth or falsity of some proposition $\mathrm{P}$, Marc is better represented as having pragmatic reasons for giving up belief in one particular proposition $\mathrm{Q}$. Both are pragmatic reasons for sure. But they support very different doxastic attitudes.

\subsection{Basing}

As we mentioned above (see Sect. 1), some evidentialists have preferred to accept as permissible only beliefs based on the believer's adequate evidence. As our case was presented, Marc's pessimistic belief was formed spuriously, that is, not based on his anterior evidence. Thus, at least initially this type of evidentialism can find fault with Marc, thus offering an evidentialist explanation of the illegitimacy of selfrationalizing pessimism. Does not this suffice to disarm our argument?

We think not. In fact, we have no significant quarrel with Marc's pessimistic belief-formation as such. Our main claim is rather that at least at some stage he ought not hold on to his pessimistic belief: At least at some stage Marc's belief is illegitimate, even though soon after its initial adoption it will in fact become based on his evidence. Since the notion of basing is controversial, we cannot hope to present a detailed argument for this claim for every account of basing proffered in the literature. Yet, arguably no matter whether Marc's basing consists in a meta-belief that his reasons are sufficient for pessimism, or in a non-deviant causal sustaining of his pessimism by his reasons, or in his treating his reasons for pessimism 
as sufficient reasons for pessimism, ${ }^{23}$ Marc ought to give up his pessimism. If the conditions stated in the antecedent of CP-weak apply, also he will be blameworthy to some degree if he does not.

\subsection{Alternative Sources of Inappropriateness?}

A last evidentialist rejoinder could be that indeed there is something wrong with Marc, yet there is nothing wrong with his pessimist belief. Rather, e.g. Marc ought to show more enthusiasm for statistics or less desire to stop work at statistical problem solving etc. So, allegedly we have misdiagnosed what is problematic about him. We shall deal with this objection swiftly: This objection is merely a change of topic; which pragmatists have any reason to regard as being beside the point. Indeed, Marc's situation may be imperfect in all sorts of ways. Yet, in no obvious way does this make it the case that he ought not give up his pessimistic belief.

\section{Conclusion}

We have argued in favour of a strong version of pragmatism to the effect that standard evidentialism does not provide us with a fully adequate ethics of belief. Specifically, we have shown that plausibly there are beliefs that standard evidentialism is bound to permit; but which the believer ought not hold. Arguably, this enjoins evidentialism to pass the wrong verdict on many mundane cases. Certain cases of self-rationalizing beliefs, we have shown, illustrate this point particularly well. We also showed that our argument adds to the case for pragmatism beyond the work already done by such authors as McCormick and Reisner. Finally, we rejected several evidentialist lines of response to our argument, considering also the dialectical resources of other popular versions of evidentialism.

Of course, we do not claim that the beliefs evidentialists okay, should not typically be permitted by an appropriate ethics of belief. As far as we are concerned, a suitably fine-tuned version of evidentialism may well be close to extensionally adequate in the sense that it gets the permissibility of beliefs perfectly right for most of the time and for most purposes. Rather, we believe that the radical consequence of our argument lies elsewhere. Standard evidentialism is built on the idea that, since generally evidence plays such a crucial role in explaining belief, the doxastic concerns in our lives are likely to be fundamentally distinct from other ethical concerns. We have argued that doxastic and ethical concerns are not, however, always distinct. A more promising idea is that ultimately all dimensions of our active lives answer to ethical norms more fundamental than narrowly truth-related ones, and that realistically sometimes we face situations where going with evidentialist norms alone risks leading us seriously astray.

\footnotetext{
23 This being, respectively, a doxastic -; a sustaining -; and a treating view of basing, arguably constituting the major basic positions on the matter (see Sylvan 2016).
} 
Acknowledgements Our work on this article has benefited from many insightful comments. We wish to thank in particular Mikkel Gerken, Rik Peels, Esben Nedenskov Petersen, Jeroen de Ridder, and the audience of the OZSW Annual Conference 2017 in Doorn.

Open Access This article is distributed under the terms of the Creative Commons Attribution 4.0 International License (http://creativecommons.org/licenses/by/4.0/), which permits unrestricted use, distribution, and reproduction in any medium, provided you give appropriate credit to the original author(s) and the source, provide a link to the Creative Commons license, and indicate if changes were made.

\section{References}

Adler, J. (2002). Belief's own ethics. New York: Bradford Books.

Arrow, K. (1998). What has economics to say about racial discrimination? Journal of Economic Perspectives, $12,91-100$.

Bénabou, R., \& Tirole, J. (2016). Mindful economics: The production, consumption, and value of beliefs. Journal of Economic Perspectives, 30, 141-164.

Benoit, R., \& Anderson, M. (2012). Opposing mechanisms support the voluntary forgetting of unwanted memories. Neuron, 76, 450-460.

Bett, R. (2014). Pyrrho. In The Stanford Encyclopedia of Philosophy, Winter 2014. https://plato.stanford.edu/ archives/win2014/entries/pyrrho/.

Bortolotti, L., \& Antrobus, M. (2015). Costs and benefits of realism and optimism. Current Opinion in Psychiatry, 28, 194-198.

Brueckner, A. (2009). E=K and perceptual knowledge. In P. Greenough \& D. Pritchard (Eds.), Williamson on knowledge (pp. 5-11). Oxford: Oxford University Press.

Carver, C., \& Scheier, M. (2014). Dispositional optimism. Trends in Cognitive Sciences, 18, 293-299.

Chignell, A. (2017). The ethics of belief. In The Stanford Encyclopedia of Philosophy, Spring 2017. https:// plato.stanford.edu/archives/spr2017/entries/ethics-belief.

Clifford, W. K. (1999). The ethics of belief. In T. J. Madigan (Ed.), The ethics of belief and other essays (pp. 70-96). New York: Prometheus Books.

DeRose, K. (2009). The case for contextualism: Knowledge, skepticism, and context (Vol. 1). Oxford: Clarendon Press.

Feldman, R. (2001). Voluntary belief and epistemic evaluation. In M. Steup (Ed.), Knowledge, truth, and duty: Essays on epistemic justification, responsibility, and virtue (pp. 77-92). Oxford: Oxford University Press.

Gilovich, T. (1991). How we know what isn't so: The fallibility of human reason in everyday life. New York: The Free Press.

Haack, S. (1997). “The Ethics of Belief” reconsidered. In L. E. Hahn (Ed.), The philosophy of Roderick M. Chisholm (pp. 129-144). Peru, IL: Library of Living Philosophers, Open Court.

Klassen, R. (2004). Optimism and realism: A review of self-efficacy from a cross-cultural perspective. International Journal of Psychology, 39, 205-230.

Machery, E. (2017). Philosophy within its proper bounds. Oxford: Oxford University Press.

Madigan, T. J. (2009). W.K. Clifford and "The Ethics of Belief". Newcastle: Cambridge Scholars Publishing.

Marušić, B. (2011). The ethics of belief. Philosophy Compass, 6(1), 33-43.

McCormick, M. S. (2015). Believing against the evidence: Agency and the ethics of belief. New York: Routledge.

Oster, E., Shoulson, I., \& Dorsey, R. (2013). Optimal expectations and limited medical testing: Evidence from huntington disease. American Economic Review, 103, 804-830.

Reisner, A. (2008). Weighing pragmatic and evidential reasons for belief. Philosophical Studies, 138, 17-27.

Reisner, A. (2013). Leaps of knowledge. In T. Chan (Ed.), The aim of belief (pp. 167-183). Oxford: Oxford University Press.

Reisner, A. (forthcoming). Pragmatic reasons for belief. In Star, D. (Ed.), The Oxford Handbook of reasons and normativity (Vol. 138/1, pp. 17-27). Oxford: Oxford University Press.

Steele, C. (2010). Whistling Vivaldi: How stereotypes affect us and what we can do. New York: Norton.

Swire, P. (1995). Equality of opportunity and investment in creditworthiness. University of Pennsylvania Law Review, 143, 1533-1559.

Sylvan, K. (2016). Epistemic Reasons II: Basing. Philosophy Compass, 11(7), 377-389.

Vahid, H. (2010). Rationalizing beliefs: Evidential Vs. Pragmatic reasons. Synthese, 176, 447-462.

Williamson, T. (2000). Knowledge and its limits. Oxford: Oxford University Press. 
Young, G. (2013). Philosophical psychopathology. Philosophy without thought experiments. London: Palgrave Macmillan.

Publisher's Note Springer Nature remains neutral with regard to jurisdictional claims in published maps and institutional affiliations. 